Research Article

\title{
Research on the Effect of Metal Electrode Coupling Voltage under Induced Electrostatic Discharge
}

\author{
Jianping Zhang $\mathbb{D}^{1,2}$ Xiaofeng $\mathrm{Hu} \mathbb{D}^{1},{ }^{1}$ Xining Xie, ${ }^{1}$ and Siyu $\mathrm{Li}^{1}$ \\ ${ }^{1}$ Shijiazhuang Campus, Army Engineering University, National Key Laboratory on Electromagnetic Environmental Effects, \\ Shijiazhuang 050003, China \\ ${ }^{2}$ Unit 32140 of PLA, Shijiazhuang 050061, China
}

Correspondence should be addressed to Xiaofeng Hu; 516510399@qq.com

Received 24 July 2020; Accepted 23 December 2020; Published 12 January 2021

Academic Editor: Guido Ala

Copyright (c) 2021 Jianping Zhang et al. This is an open access article distributed under the Creative Commons Attribution License, which permits unrestricted use, distribution, and reproduction in any medium, provided the original work is properly cited.

In this paper, the mechanism of electrostatic discharge induced by a strong electromagnetic field was studied through software simulation and test verification. By focusing on the effect mechanism of coupling voltage between metal electrodes to induce electrostatic discharge, we obtained the law of electrostatic discharge induced by the strong electromagnetic field. In the process of electrostatic discharge induced by the strong electromagnetic field, due to the antenna receiving effect of metal electrode structure, the strong electromagnetic field would form coupling induction voltage on the metal electrode. The voltage acts on both ends of the discharge electrode structure and generates an electric field in the gap between the electrode structure, which superimposes on the original field; furthermore, it has an impact on the electrostatic discharge process, resulting in the formation of induced discharge with low charging voltage structure.

\section{Introduction}

Electrostatic discharge in an electromagnetic environment of spacecraft is a complex process, which is related to the space environment, spacecraft structure, size, and material performance [1-3]. For space equipment, electrostatic discharge induced by the strong electromagnetic field refers to the process of electrostatic discharge induced in the low charge potential area of spacecraft surface materials, cables, and some special structural components under the action of the external strong electromagnetic field [4-9]. In general, the electric field in the sensitive area of low charge potential on the surface of spacecraft is weak [10-15], the electron energy is lower than the ionization energy of molecules and atoms [16-23], and the probability of collision ionization is low $[24,25]$. When subjected to a strong electromagnetic field, the low-pressure gas is excited to produce dense plasma [24-27], to reduce the discharge threshold and induce electrostatic charge discharge $[28,29]$. It is of great significance to master the influence and mechanism of the strong electromagnetic field on electrostatic discharge process [30] and to study the law of electrostatic discharge induced by the strong electromagnetic field in space equipment [31].

In this paper, the needle-ball electrode was taken as the research object, and an ultra-wideband electromagnetic pulse was used to build a strong electromagnetic environment. The simulation model of the needle-ball electrode strong electromagnetic field coupling voltage was established by using CST software. The coupling voltage and gap electric field distribution of different lengths and sizes of metal electrodes were calculated, and the influence law of the polarization direction of strong electromagnetic field, the amplitude of field strength, and the size of metal electrode on the coupling voltage were studied. The experiment system of ultra-wideband electromagnetic pulse induced discharge with a needle-ball electrode was developed to study the influence of electrode size, amplitude of ultra-wideband electromagnetic pulse field, and polarization direction on the threshold value of induced discharge. The influence of the coupling voltage of metal electrode on induced discharge was analyzed by comprehensive simulation, calculation, and test results. 


\section{Establishment of the Simulation Model}

2.1. Simulated Test Model. As shown in Figure 1, the simulation software CST microwave studio was used for modeling. The detailed parameter settings are as follows: the needle electrode was perpendicular to the surface of the ball electrode, the needle direction coincided with the $z$-axis direction, the electrode material was PEC, and the space was filled with vacuum. When the diameter of the spherical electrode was $15 \mathrm{~cm}$, the coupling voltage and spatial electric field distribution were simulated by changing the electrode length or electrode spacing.

2.2. Parameter Settings. Figure 2 displays the ultra-wideband electromagnetic pulse signal that we simulated for irradiation. The excitation signal was a plane wave, whose working frequency was set between $0 \mathrm{GHz}-1 \mathrm{GHz}$, and the center frequency was set at $0.5 \mathrm{GHz}$. The polarization direction was linear polarization, and the propagation direction of the electromagnetic wave signal was vertical or horizontal to the direction of the needle. Simulation calculation was carried out by changing the electric field intensity of the excitation signal or the polarization direction of the excitation signal.

2.3. Measurement Settings. We placed a voltage monitor between the needle and the ball electrode to measure the change of the induced voltage between the needle and the ball; we also placed 5 electric field probes between the needle and the ball electrode, from $0.5 \mathrm{~mm}$ to $2.5 \mathrm{~mm}$ to the needle tip, to monitor the change of the induced field strength in the discharge channel.

\section{Analysis of Simulation Results}

Without changing other conditions, a single variable was changed to carry out the simulation calculation, and then, the relationship between the induced electric field and the variable was analyzed.

\subsection{Influence of Polarization Direction of the External Electric} Field. Under other conditions, unchanged, the relative polarization direction of the excitation signal and the needle electrode was changed to study the relationship between the direction of induced voltage or field strength between the poles and the polarization direction of the applied excitation signal.

The simulation parameters are set as follows: the needle electrode length was $30 \mathrm{~cm}$, the distance between the electrodes was $3 \mathrm{~mm}$, the needle ball electrode was arranged vertically, the load resistance was $10 \mathrm{ohm}$, and the capacitance was $500 \mathrm{pf}$ between the electrodes; the applied electric field amplitude was $100 \mathrm{kV} / \mathrm{m}$; the electric field probes were, respectively, placed at the tip of the needle electrode of $0.5 \mathrm{~mm}, 1 \mathrm{~mm}, 1.5 \mathrm{~mm}, 2 \mathrm{~mm}$, and $2.5 \mathrm{~mm}$ to test the electric field distribution at the gap. The voltage signal induced by the applied horizontally polarized electric field is shown in Figure 3, and the distribution of the induced electric field component corresponding to the gap channel direction at different positions is shown in Figure 4. The voltage signal induced by the applied vertical polarized electric field is shown in Figure 5, and the peak distribution of the induced electric field component in the gap channel direction at different positions is shown in Figure 6. The 2D distribution diagram of the induced electric field is shown in Figure 7.

As can be seen from Figure 3 that when the applied electric field direction was perpendicular to the metal needle electrode, the coupling voltage of the metal needle electrode was very small and consequently could be ignored; Figure 4 shows us that the maximum component of the electric field formed in the gap along the gap direction was not more than $1 \mathrm{~V} / \mathrm{m}$, that is, when the needle electrode was perpendicular to the applied electric field direction, the induced field strength was very small and hence could be ignored.

According to Figures 5 and 6, we can find that when the direction of the applied electric field was parallel to the metal needle electrode, the peak value of the coupling voltage of the metal needle electrode reached $939 \mathrm{~V}$, and the peak value of the electric field formed at the gap reached $106 \mathrm{~V} / \mathrm{m}$, an order of magnitude larger than the amplitude of the applied electric field, thereby the electrostatic discharge process of the gap could not be ignored.

It can be seen from Figures 6 and 8 that, in the discharge channel, the closer to the tip of the needle, the greater the induction field strength would be, and the closer to the spherical surface, the more uniform the induction field strength, which is in accordance with the law that the larger the curvature of the conductor is, the more serious the electric field distortion is.

\subsection{Influence of the Peak Value of the External Electric Field.} The simulation parameters were set as follows: the needle electrode length was $30 \mathrm{~cm}$; the radius of the ball electrode was $15 \mathrm{~cm}$; the distance between the poles was $3 \mathrm{~mm}$; the needle electrode was arranged vertically; a load resistance of $10 \mathrm{ohm}$ and capacitance of $500 \mathrm{pf}$ was added between the electrodes; the electric field probe was placed $0.5 \mathrm{~mm}$ away from the tip of the needle in the gap channel; the applied electric field was vertically polarized, and then, its peak value was constantly changed to facilitate the study of the peak value and induced voltage of the applied electric field and gap induced electric field.

The relationship between the peak value of the induced voltage of the metal electrode and the peak value of the applied electric field is shown in Figure 9, while the relationship between the peak value of the induced electric field and the peak value of the applied electric field at $0.5 \mathrm{~mm}$ of the tip of the gap channel is shown in Figure 10.

Figures 9 and 10 show us that the peak field strength of the induced voltage between the metal electrodes and the peak field strength of the induced electric field at $0.5 \mathrm{~mm}$ of the tip of the gap channel is directly proportional to the peak value of the applied electric field. It also can be seen from Figure 10 that the induced field intensity is one order of magnitude larger than the peak value of the applied electric field, which has a greater impact on the discharge process of the gap channel than the applied electric field. 


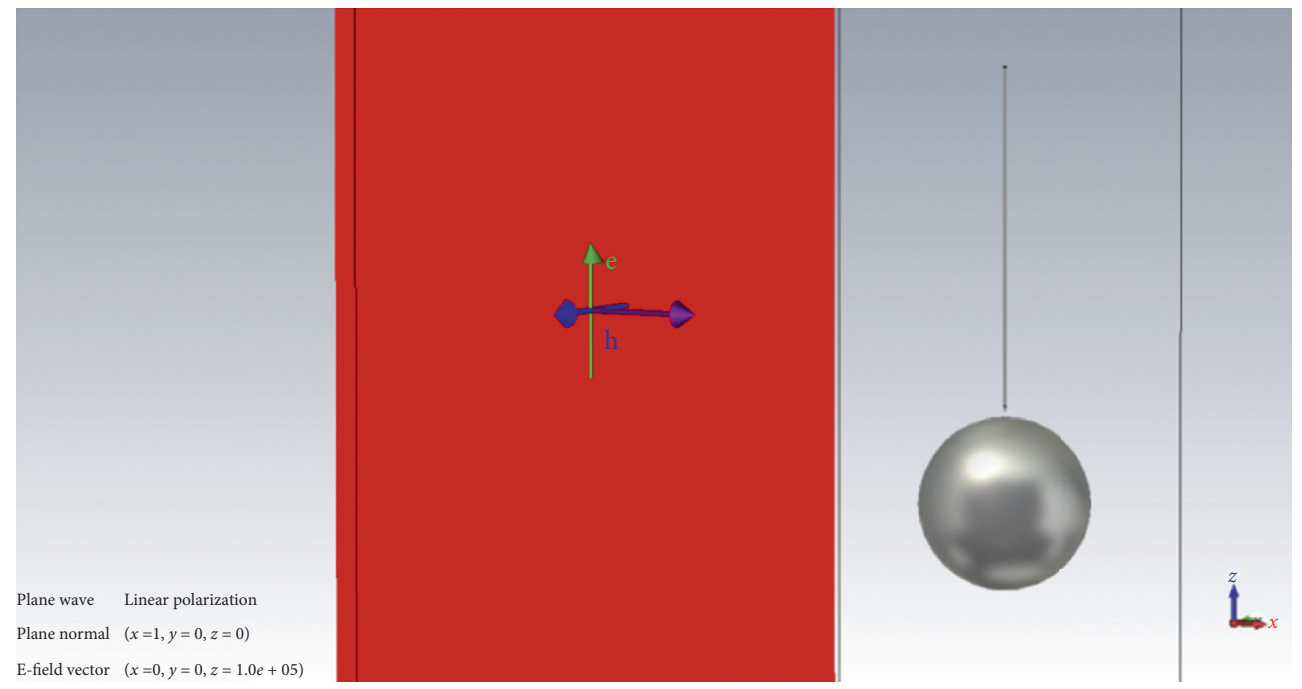

FIgURE 1: The Simulation Model of needle-ball electrode structure.

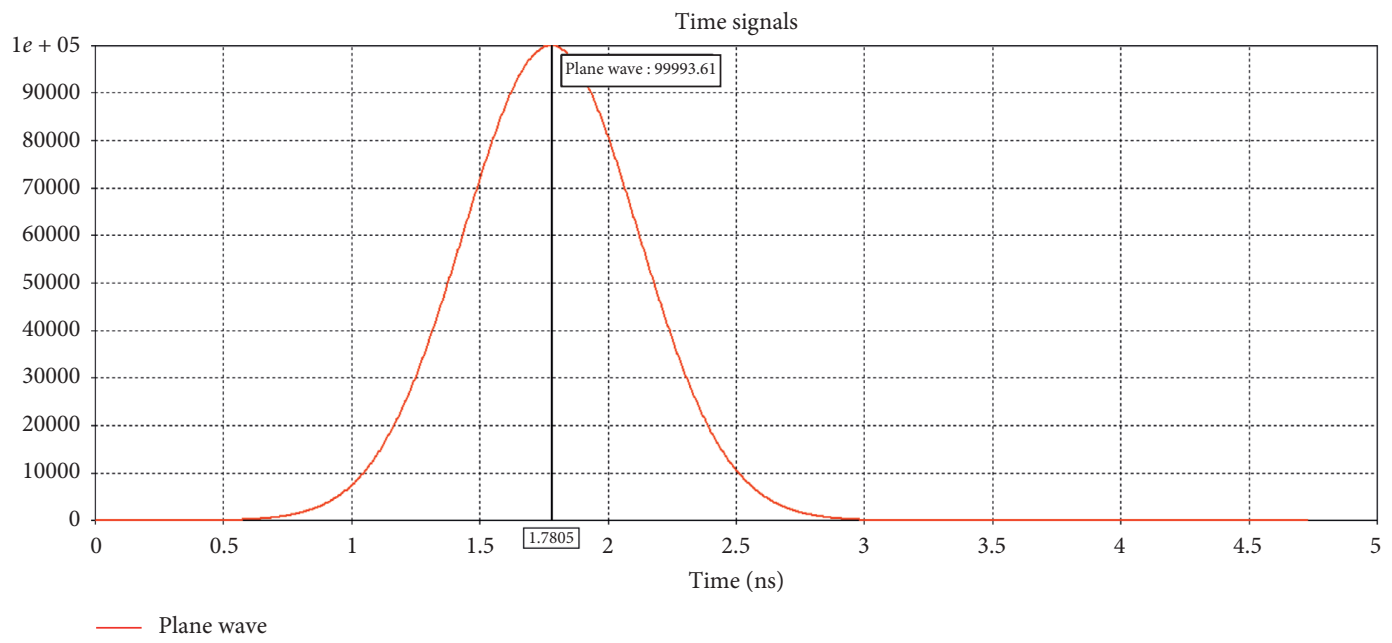

Figure 2: UWB simulation signal.

3.3. Influence of Electrode Size. The simulation parameters were set as follows: the distance between electrodes was $3 \mathrm{~mm}$; the needle electrode was placed vertically; the peak value of the applied electric field was $100 \mathrm{kV} / \mathrm{m}$; the applied electric field was polarized vertically; first, when the diameter of metal ball was $15 \mathrm{~cm}$, we adjusted the needle electrode length, which was set as $10 \mathrm{~mm}, 40 \mathrm{~mm}$, $80 \mathrm{~mm}, 120 \mathrm{~mm}, 150 \mathrm{~mm}, 300 \mathrm{~mm}, 450 \mathrm{~mm}, 600 \mathrm{~mm}$, $750 \mathrm{~mm}$, and $900 \mathrm{~mm}$, respectively, to study the relationship between the induced voltage and the needle electrode length; then, we changed the size of the metal ball and readjusting the length of the electrode, for analysing the effect of the size of the ball electrode on the induced voltage.

Figure 11 displays the relationship between the induced peak voltage and the needle electrode length under different ball diameters, and Figure 12 shows the relationship between the induced peak voltage and the size of the ball electrode for different needle electrode lengths.
Figure 13 reveals the relationship between the frequency corresponding to the induced peak electric field and the electrode length for different ball diameters.

The simulation results show that when the electrode size was very small, the peak field strength of the induced electric field was one order of magnitude lower than that of the external radiation field. Therefore, the external radiation field played a major role in the electrostatic discharge induction process; when the electrode size was large, the peak field strength of the induced electric field was one order of magnitude higher than that of the external radiation field; consequently, the induction field strength of the metal electrode played a major role in the electrostatic discharge induction process. Figure 11 displays that when the diameter of the ball was fixed, in a certain range, the induced peak voltage increased with the increase of the length of the needle electrode, but when it exceeded over a certain range, the induced peak voltage did not change anymore, and the maximum induced peak value increased with the increase of the diameter of the ball. Figure 12 shows that when the needle 


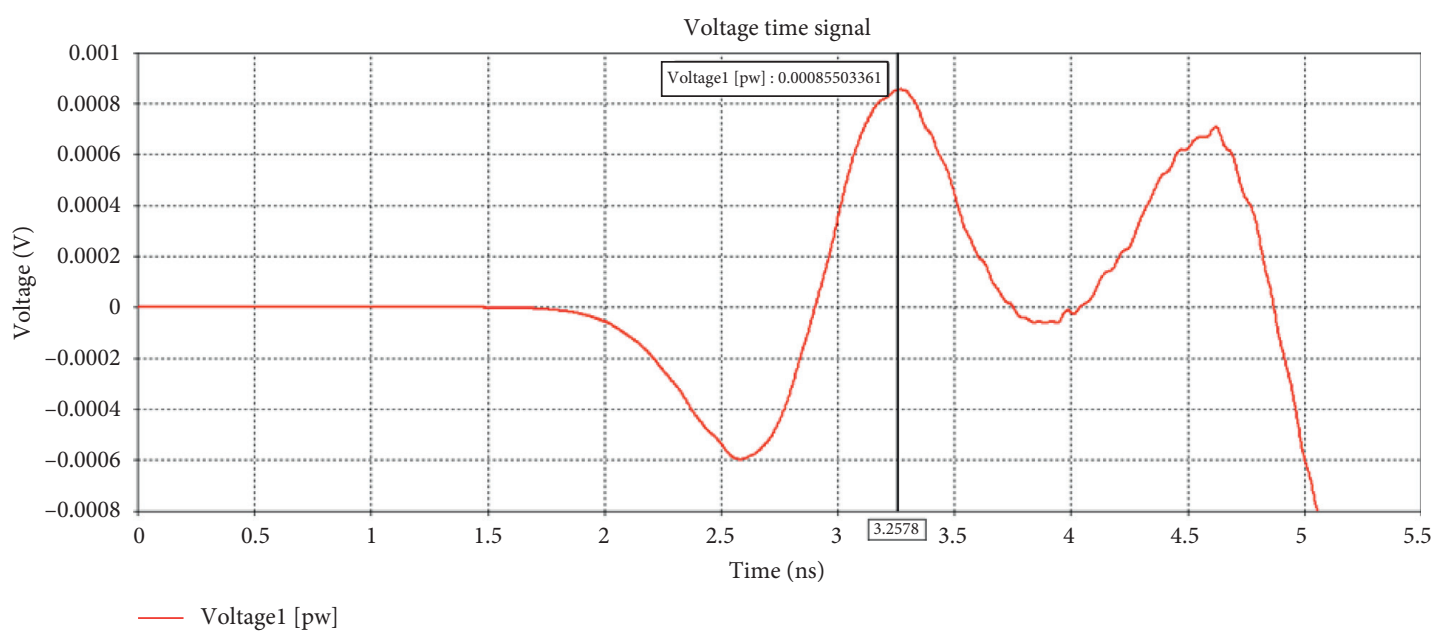

FIgURE 3: The time-domain waveform of induced voltage signal in horizontal polarization of applied electric field.

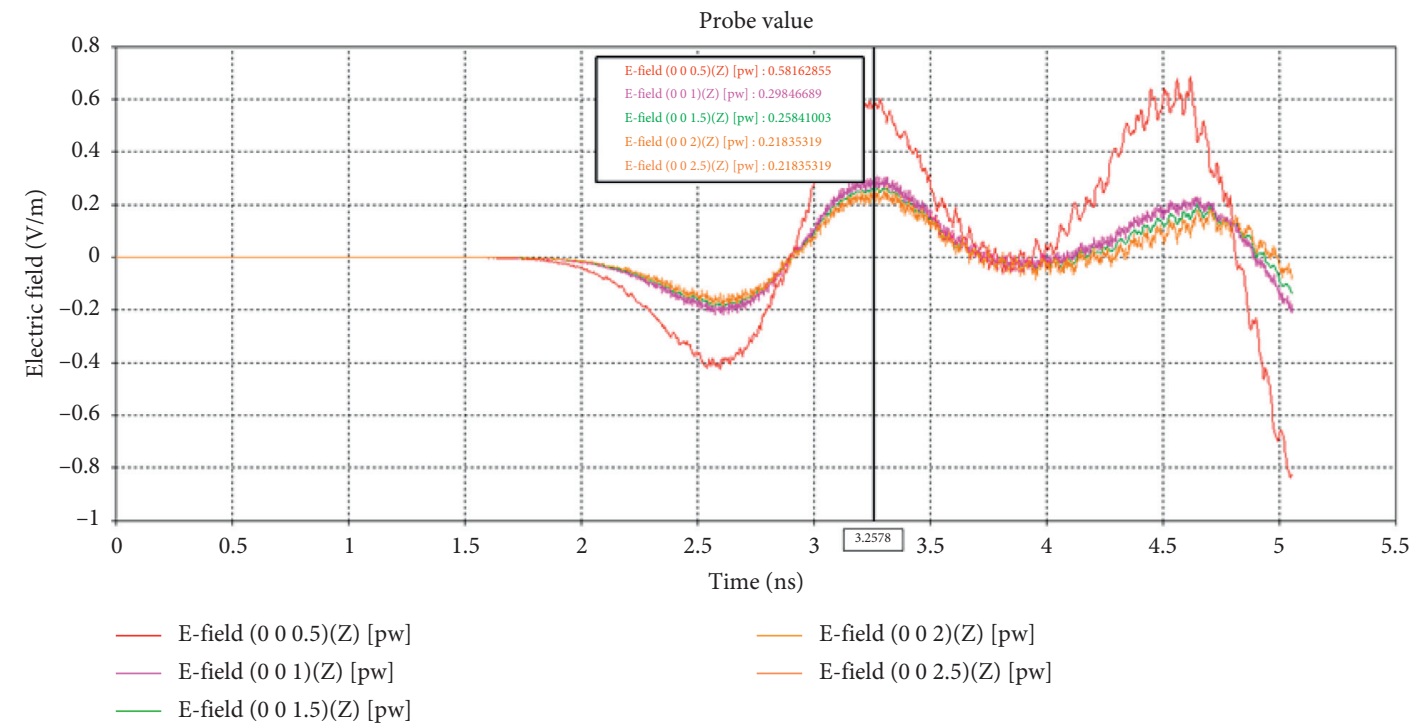

FIgURE 4: The peak distribution of electric field components in the direction of gap channel at different positions during horizontal polarization.

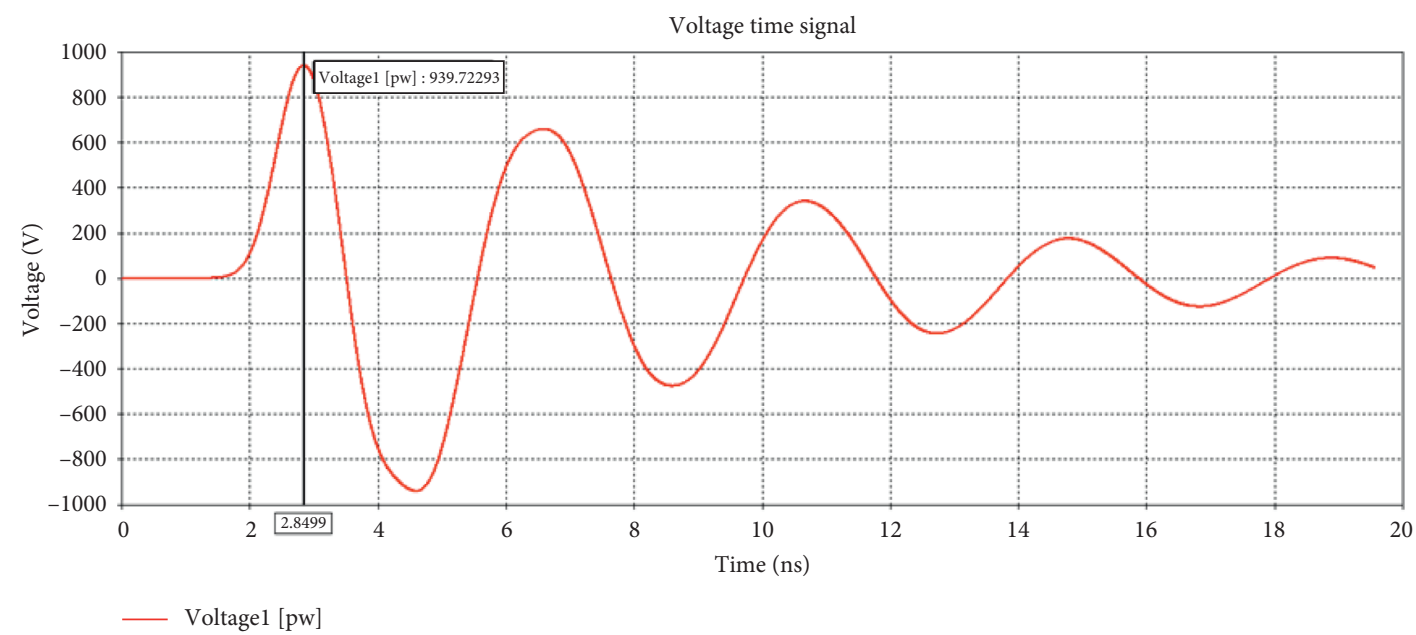

FIGURE 5: The time-domain waveform of induced voltage signal in vertical polarization of applied electric field. 


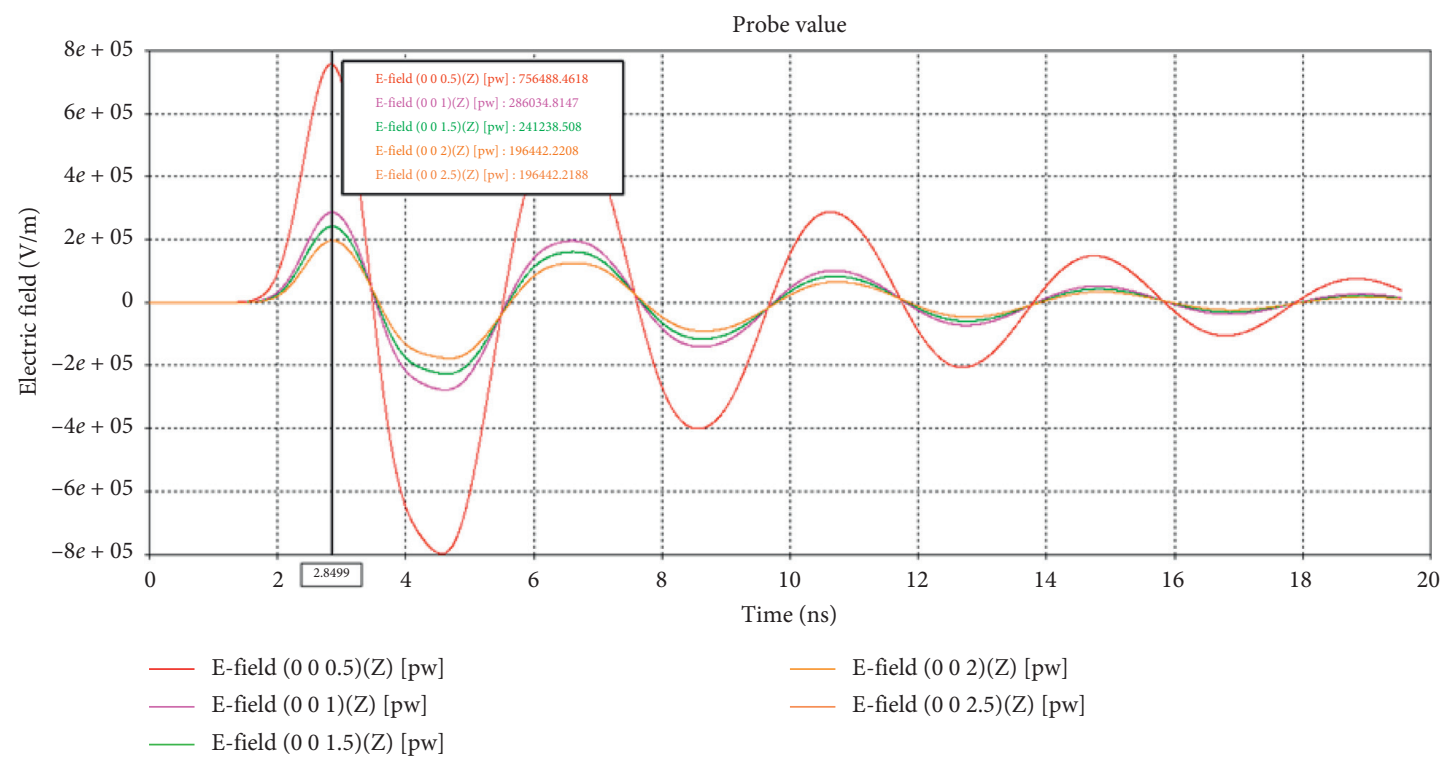

FIGURE 6: The peak distribution of electric field components in different positions in the direction of gap channel, when the electric field was vertically polarized.

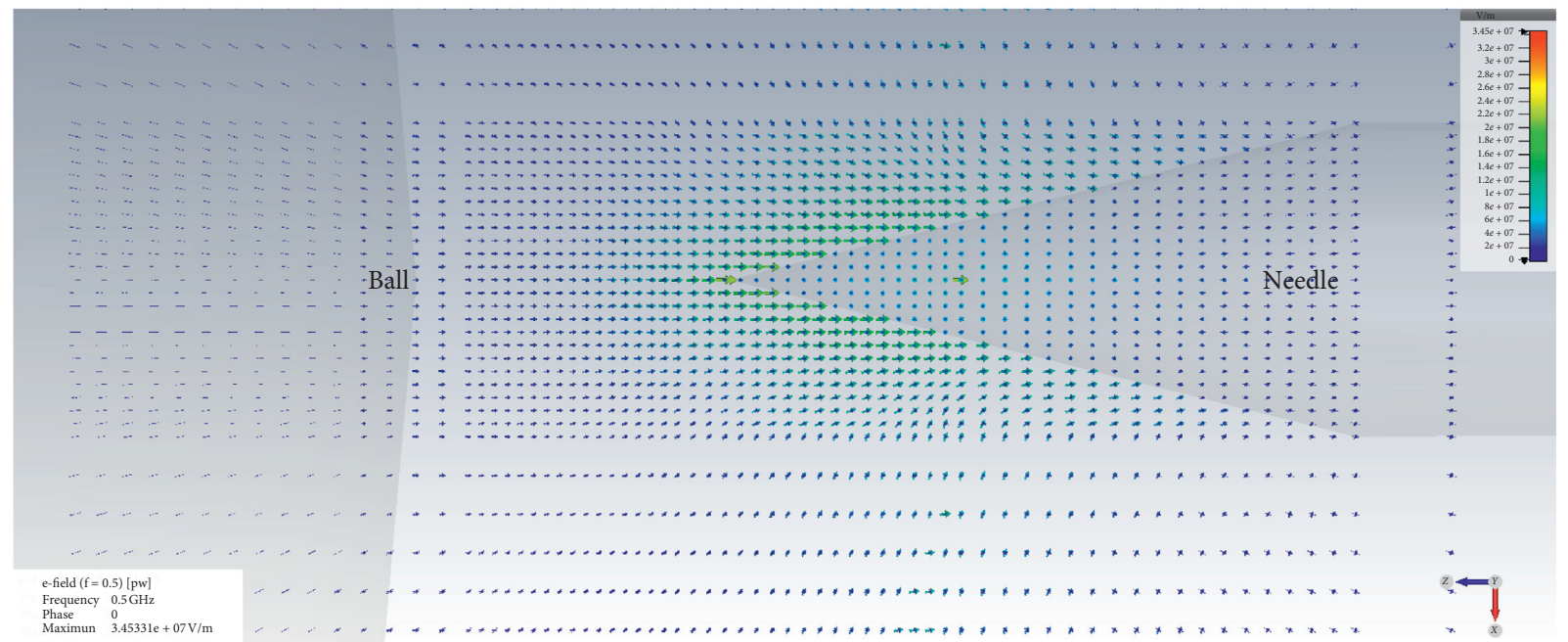

FIgURE 7: The distribution of induction field strength of needle ball electrode.

electrode length was fixed, the induced peak voltage increased with the increase of the diameter of the spherical electrode in a certain range, but when it exceeded over a certain range, the induced peak voltage did not increase anymore either. However, the maximum value of the induced voltage varied with the length of the needle electrode. Figure 13 reveals that the frequency corresponding to the peak value of the induced electric field would decrease gradually with the increase of the electrode size. And this conforms to the principle that the half-wave antenna has the strongest ability to receive electromagnetic waves.

3.4. Effect of Gap Size. The simulation parameters were set as follows: the length of needle electrode was $300 \mathrm{~mm}$, the diameter of ball electrode was $15 \mathrm{~cm}$, and the applied electric field was $100 \mathrm{kV} / \mathrm{m}$. The direction of electric field was vertical polarization, and the electric field probe was placed at $0.5 \mathrm{~mm}$ from the gap channel to the needle tip. The distance between electrodes was adjusted to $1 \mathrm{~mm}, 2 \mathrm{~mm}, 3 \mathrm{~mm}$, $6 \mathrm{~mm}, 12 \mathrm{~mm}$, and $24 \mathrm{~mm}$, respectively, to study the influence of gap size on the induced voltage and the induced electric field. The direction of the electric field is vertical polarization. The direction of the electric field was vertical polarization.

The relationship between the peak value of induced voltage and the peak value of induced electric field and the size of electrode gap distance is shown in Figures 14 and 15.

It could be seen from Figure 14 that with the increase of electrode gap distance, the peak value of induced voltage would gradually increase, but the increment was relatively 


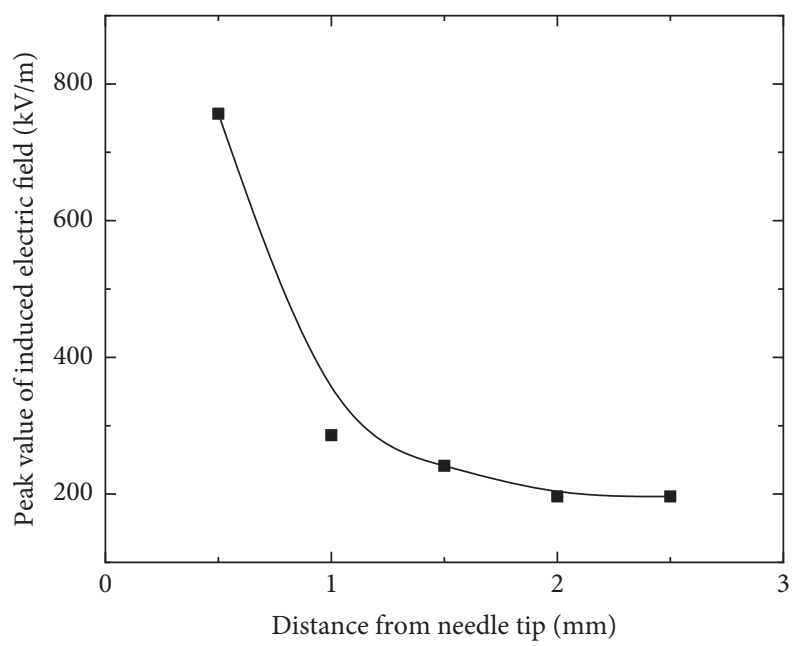

FIGURE 8: The relationship between the peak value of the induced electric field and the distance to the tip of the needle.

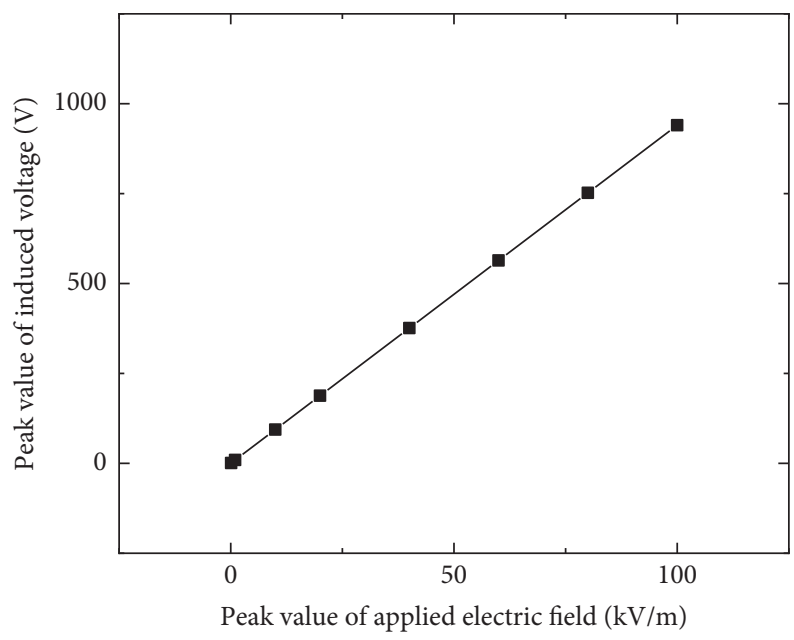

FIGURE 9: The relationship between induced peak voltage and peak value of applied electric field.

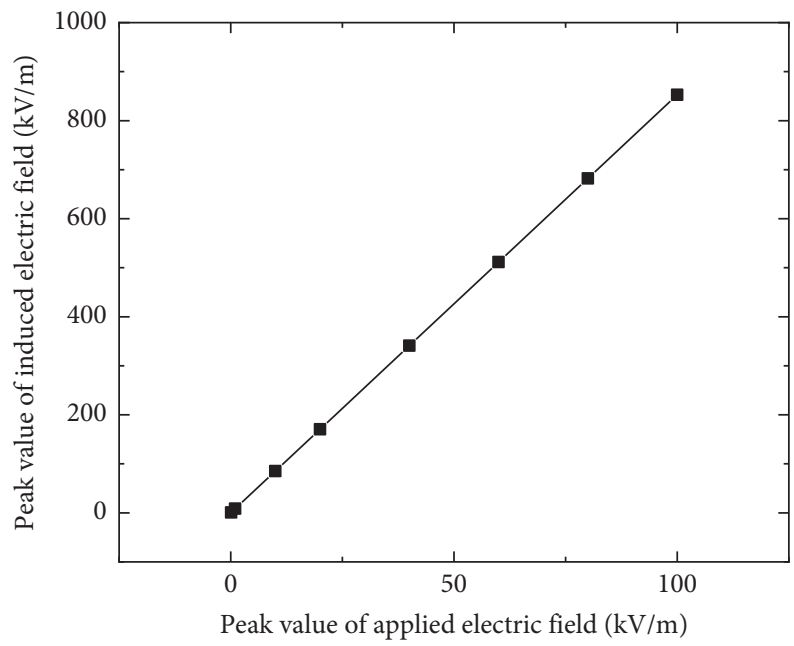

FIgURE 10: The relationship between peak field strength of induced electric field and peak value of applied electric field. 


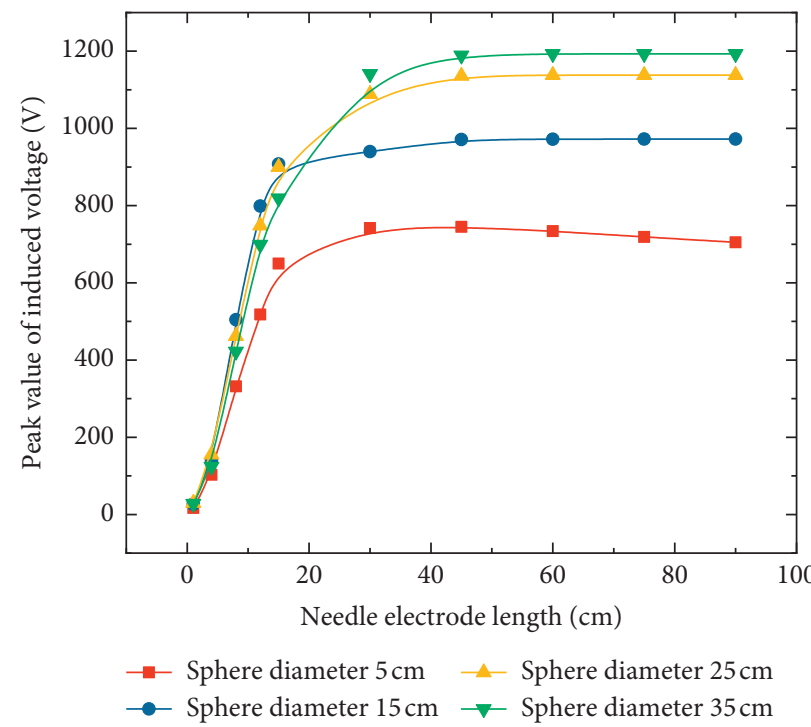

FIGURE 11: The relationship between peak induced voltage and needle electrode length.

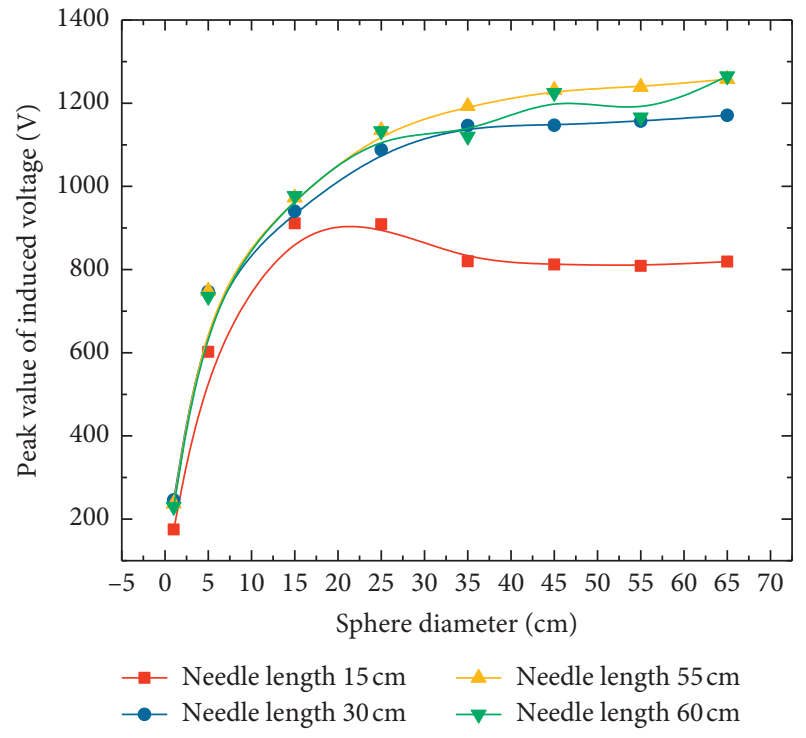

FIGURE 12: The relationship between the induced peak voltage and the ball diameter.

small. It could also be found out from Figure 15 that with the increase of the gap, when the electrode gap was $2 \mathrm{~mm}$, the maximum induction field strength was $0.5 \mathrm{~mm}$ from the tip of the needle electrode; with the increase or decrease of the gap, the induction field strength would rapidly drop; however, when the gap distance exceeded over $5 \mathrm{~mm}$, the peak value of the induction field at the needle electrode tip would gradually rose with the increase of the gap, which was caused by the gradual increase of the induction voltage.

\section{Test Verification}

To verify the effect of the metal-electrode coupling voltage on the induced electrostatic discharge, in this project, we have taken ultra-wideband electromagnetic pulse as the radiation source and needle ball electrode as the research object, and then, tested and verified the simulation results. The verification test consisted of two parts: one part was the verification test of induced voltage coupling law of the needle ball electrode under the action of the external radiation field; the other part was the verification of induced threshold law of different length electrode under the action of the external radiation field. Through the analysis of the test results, we obtained the law of the effect of the polarization direction of the electromagnetic field and the length of the electrode on the induced electrostatic discharge, to verify the correctness of the simulation conclusion of the influence of the coupling voltage of the metal electrode in the process of the induced electrostatic discharge.

In the test, the test parameters were set as follows: the needle discharge gap was set as $3 \mathrm{~mm}$; the discharge needle length was set as $900 \mathrm{~mm}, 750 \mathrm{~mm}, 600 \mathrm{~mm}, 450 \mathrm{~mm}, 300 \mathrm{~mm}$, $150 \mathrm{~mm}$, or $100 \mathrm{~mm}$, respectively; the needle electrode voltage was supplied by a GLOW28720 DC high-voltage source; the GW level UWB electromagnetic pulse radiation source was selected as the ultra-wide charged magnetic pulse source, which could provide the maximum vertical polarized electromagnetic pulse field of $80 \mathrm{kV} / \mathrm{m}$; the induced current voltage and induced discharge current were collected by using a Tektronix TDS7404 B oscilloscope through voltage and current probe (Tektronix RMS CAT, $5 \mathrm{~mA} / \mathrm{mV}$ ). During the test, the temperature was $26.9 \pm 0.5^{\circ} \mathrm{C}$; the humidity was $63.6 \%$; the air pressure was 1 standard atmospheric pressure. 


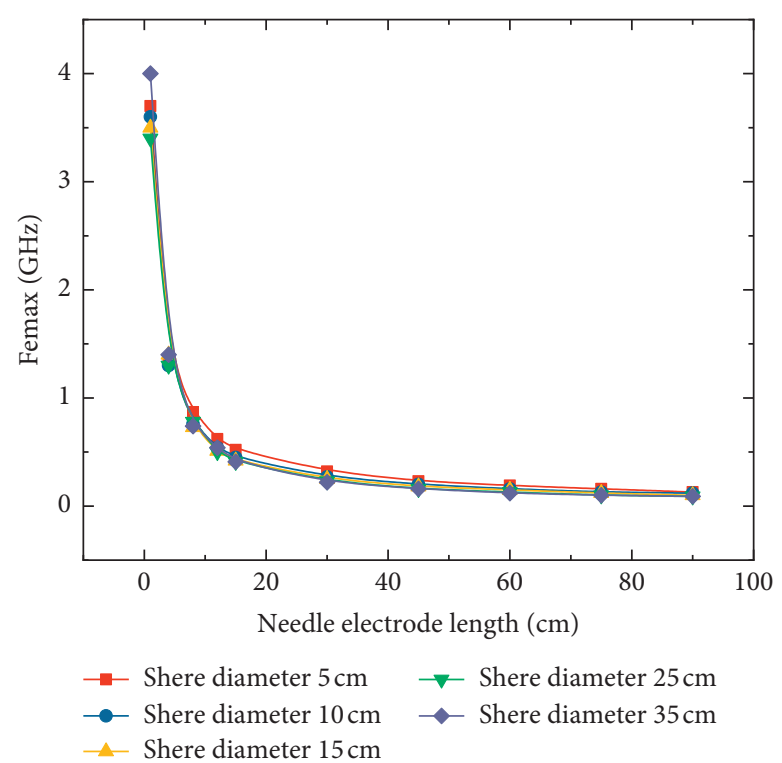

Figure 13: The relationship between frequency corresponding to peak electric field and length of needle electrode.

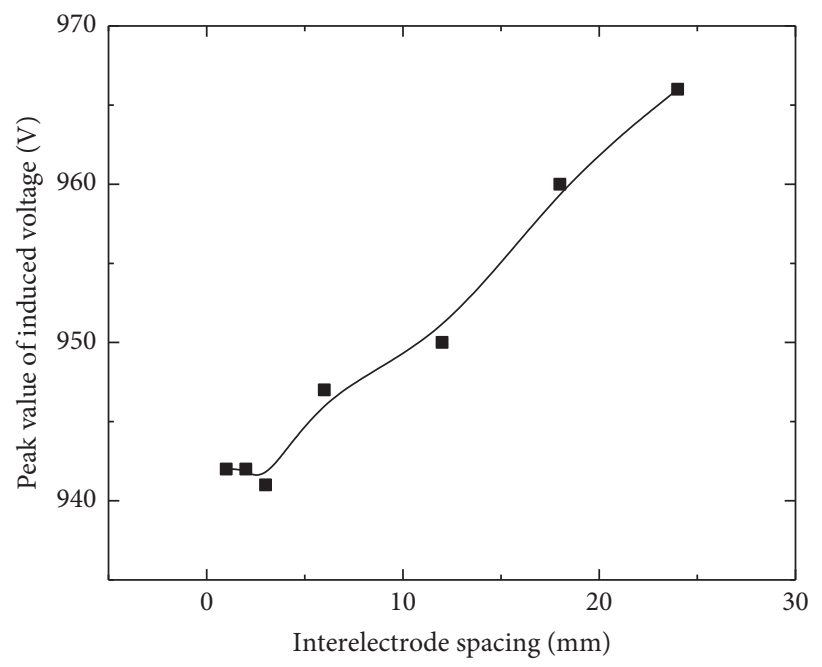

FIGURE 14: The relationship between peak value of induced voltage and electrode gap distance.

4.1. Measurement and Result Analysis of Induced Voltage of the Metal Electrode. As shown in the schematic diagram of the metal electrode induced voltage test in Figure 16, a high voltage probe was used for the induced voltage test. During the test, the test connecting wire should be shielded. At the moment of electromagnetic pulse irradiation, there would generate an induced coupling voltage of the transient electric field between the needle and the ball electrode, and it would be measured and recorded by the voltage probe and oscilloscope. Each group of experiments was repeated 5 times to ensure the repeatability and accuracy of the test data.

During the experiment, the metal needle electrode was placed in the horizontal direction or the vertical direction, respectively. Under the irradiation of ultra-wideband electromagnetic pulse, the induced voltage of different length metal electrodes was measured. The waveform fields shown in Figure 17 are, respectively, the coupling voltage of the test cable under GW level ultra-wideband electromagnetic pulse irradiation, with $100 \mathrm{~mm}, 600 \mathrm{~mm}$, or $900 \mathrm{~mm}$ metal electrodes placed horizontally, or without metal electrodes.

It can be seen from Figure 17 that the length of the discharge needle placed in the horizontal direction had little effect on the value of the induced voltage, and it was similar to the induced voltage on the test cable when no metal electrode is added. This was because the ultra-wideband was a vertically polarized electromagnetic wave, and its component in the horizontal direction was very small, so the value of the induced voltage in the horizontal direction did not change because of the length of the needle change.

Figure 18 shows the coupling voltage waveform between the metal electrodes of different lengths and the test cable without the metal electrode, under the irradiation of ultra 


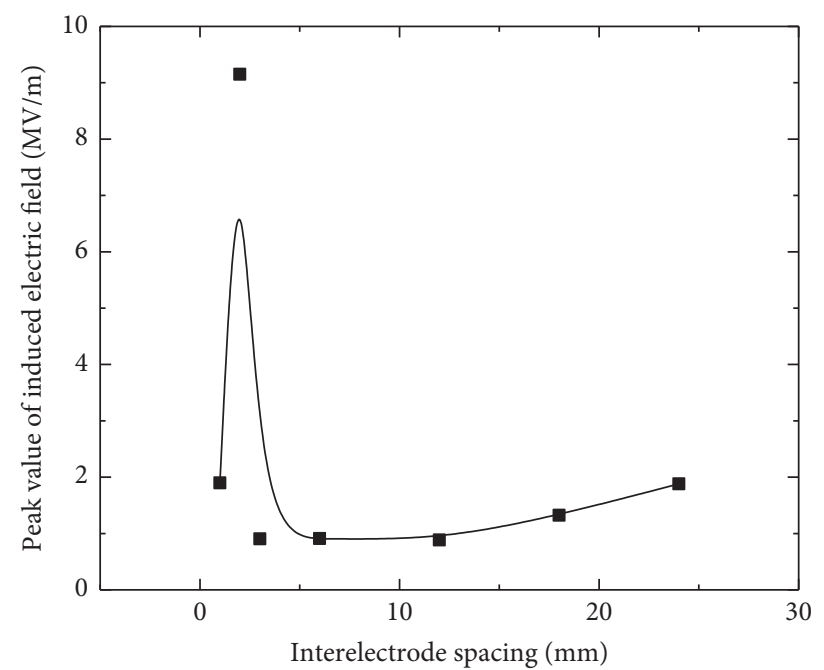

FIGURE 15: The relationship between peak value of induced electric field and electrode gap distance.

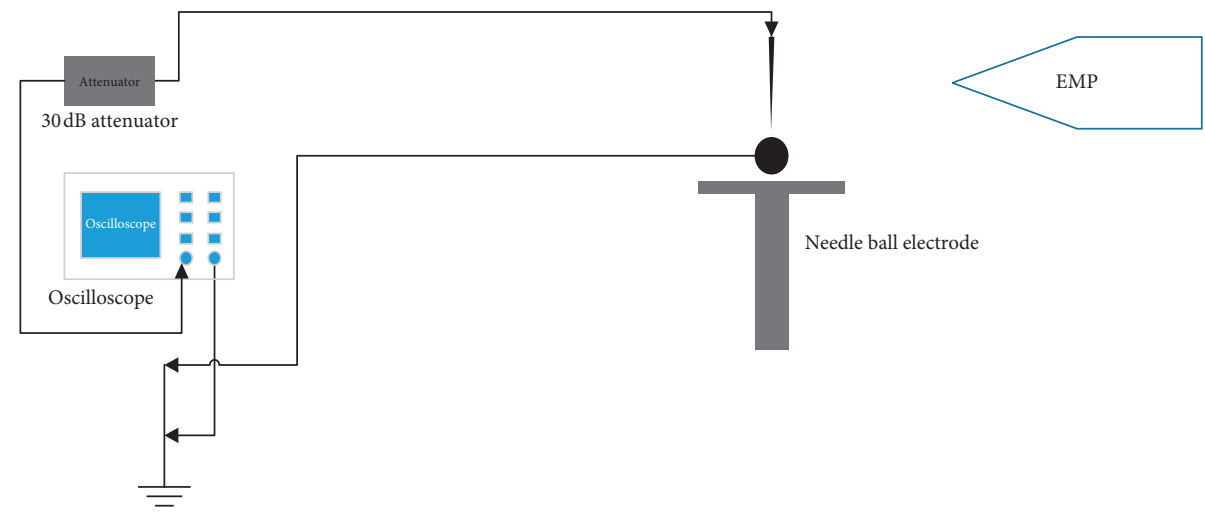

FIgURE 16: Schematic diagram of induced voltage measurement.

wide band electromagnetic pulse, when the metal electrode was placed vertically, that is, when the direction of the electrode was consistent with the polarization direction of the external ultra wide band electromagnetic pulse.

It can be seen from Figure 18 that the induced voltage value of the needle with the length of less than $300 \mathrm{~mm}$ has no change. At the same time, compared with Figure 18(h), it is found that the induced voltage on the test cable without the metal electrode is greater than the induced voltage with the needle length of less than $300 \mathrm{~mm}$, and the test cable has a great impact on the verification of the coupling voltage rule. According to the analysis of the induced voltage test data of the $450 \mathrm{~mm}-900 \mathrm{~mm}$ discharge needle, the induced voltage value is also increasing with the increasing of the length of the discharge needle. The relationship between the induced voltage and the length of different discharge needles is shown in Figure 19.

By comparing the induced voltage waveform of the discharge needle length of $900 \mathrm{~mm}$ in Figures 18 and 19, it can be seen that when the direction of the needle ball electrode was consistent with the polarization direction of the external ultra-wideband electromagnetic pulse, the induced voltage was greater than that when they were vertical.
Therefore, the coupling voltage of the metal electrode had a great relationship with the polarization direction of the external electromagnetic field. When the direction of the metal electrode was the same as that of the external electromagnetic field, the induced discharge process of the electrode would be affected by the external electromagnetic field. When the direction of the metal electrode was perpendicular to the polarization direction of the external electromagnetic field, the influence of the metal electrode's coupling voltage on the discharge process induced by the electromagnetic field could be ignored, which is consistent with the simulation results.

4.2. Measurement and Analysis of Induced Threshold of Different Lengths of Metal Electrodes. To further verify the influence of the different lengths of electrodes on the threshold of discharge induced by electromagnetic field, this project carried out the experimental research of the different lengths of electrodes induced discharge. The principle diagram of the induced discharge threshold test is shown in Figure 20, and the test site is shown in Figure 21. In this experiment, firstly, we had to find out the threshold value of spark 


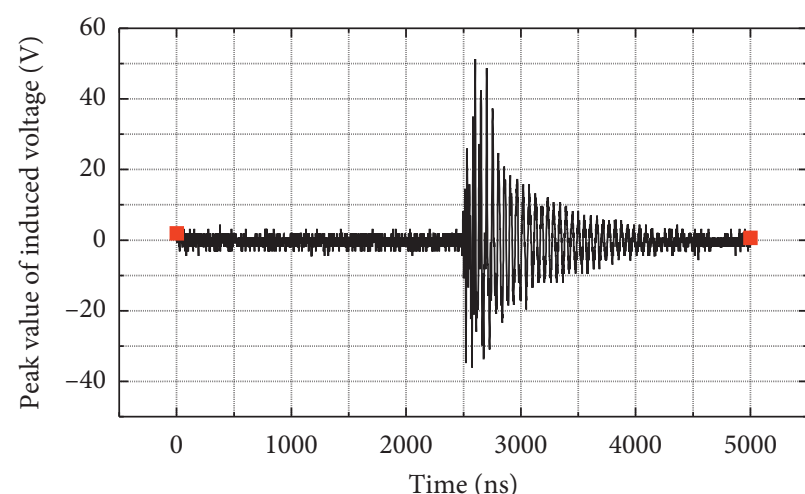

(a)

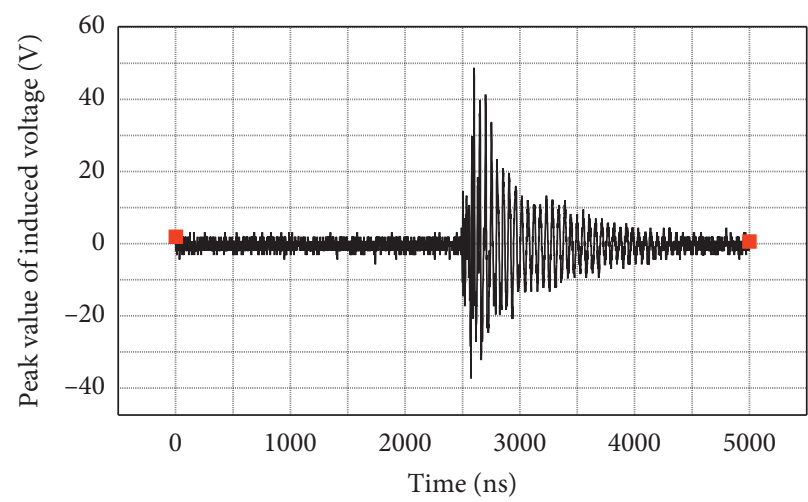

(c)

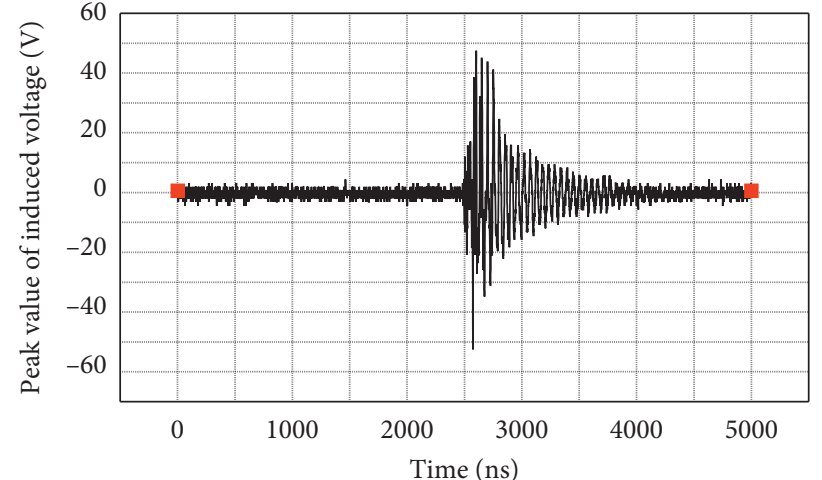

(b)

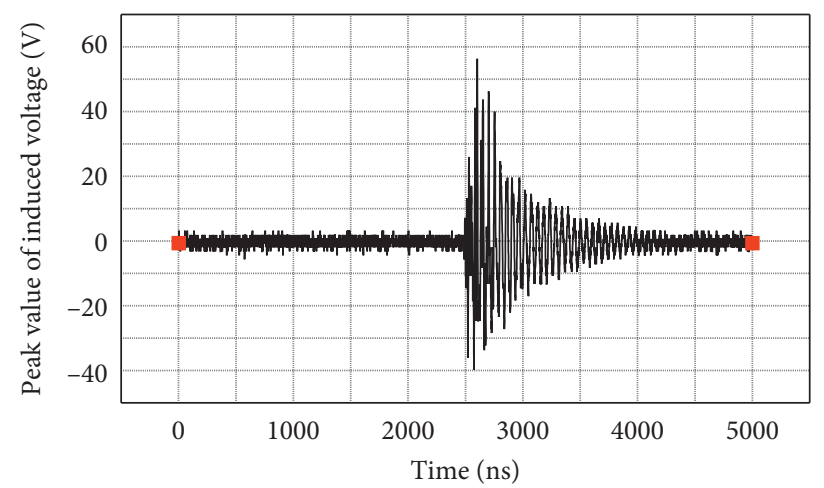

(d)

FIGURE 17: Induced voltage of discharge needle with different length in horizontal direction. (a) $100 \mathrm{~mm}$. (b) $600 \mathrm{~mm}$. (c) $900 \mathrm{~mm}$. (d) Without metal electrode.

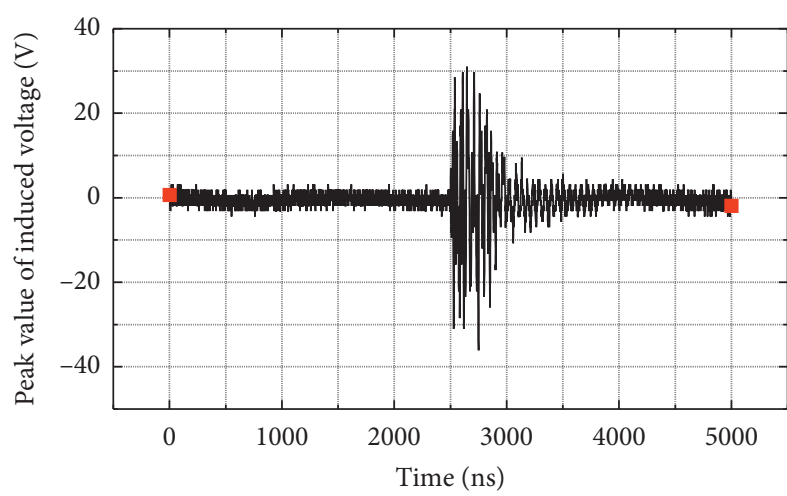

(a)

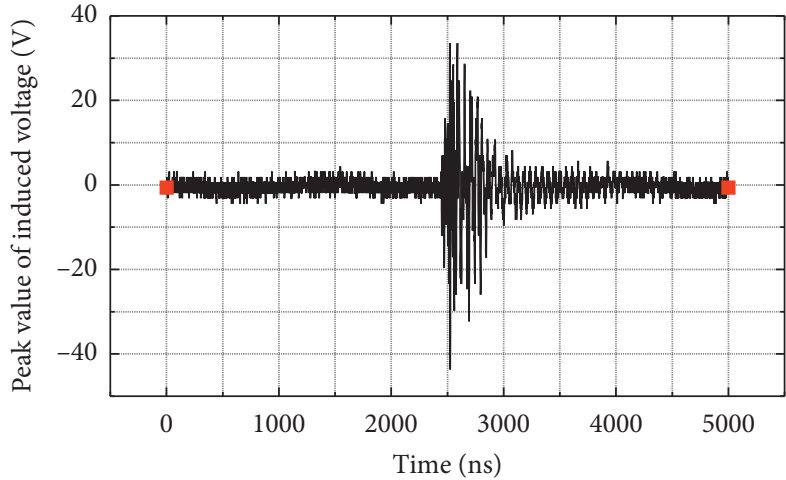

(c)

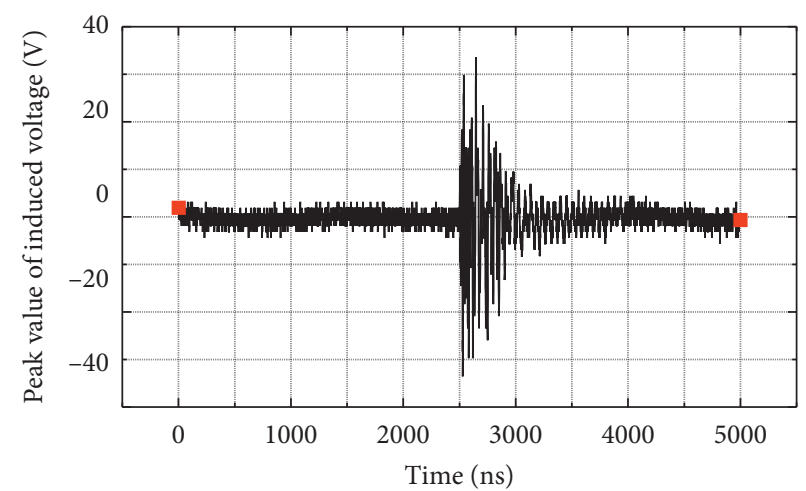

(b)

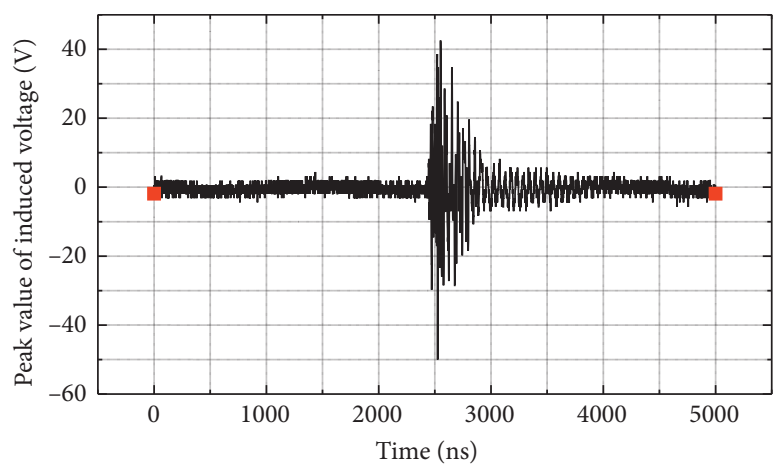

(d)

FIGURE 18: Continued. 


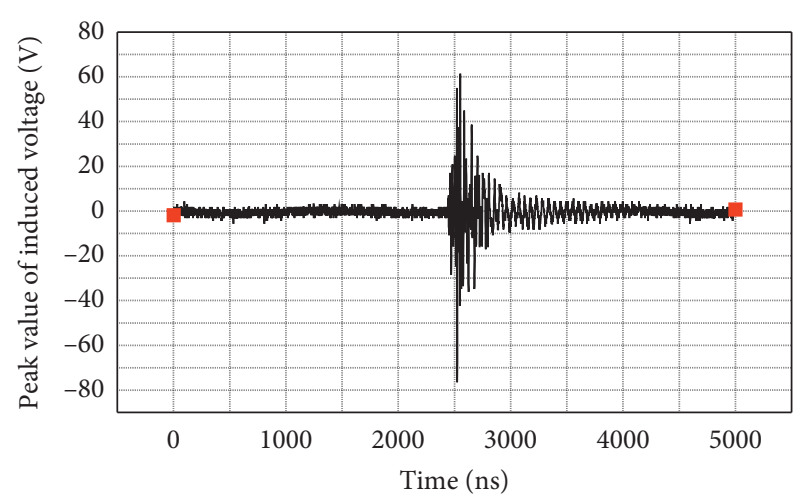

(e)

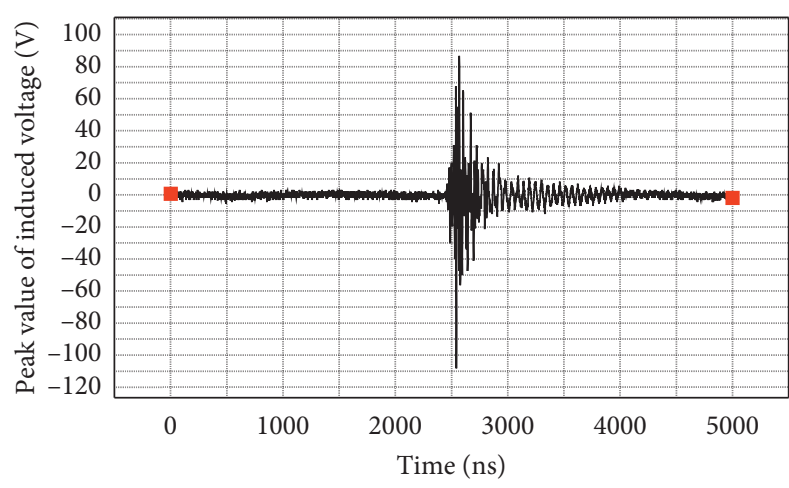

(g)

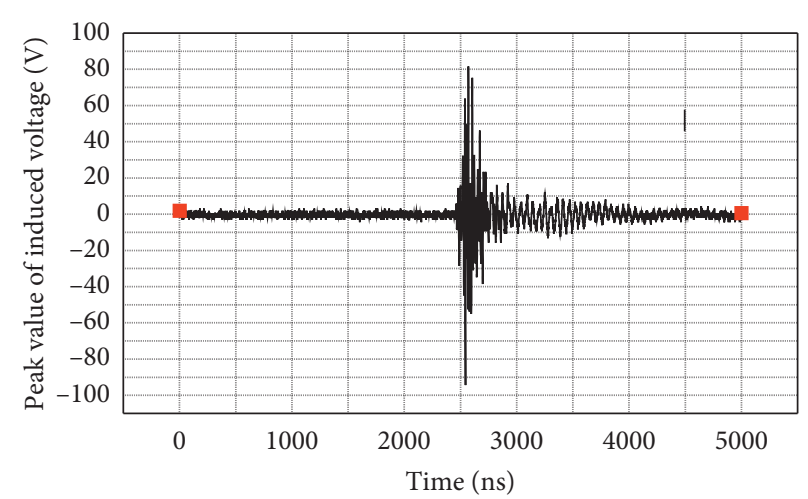

(f)

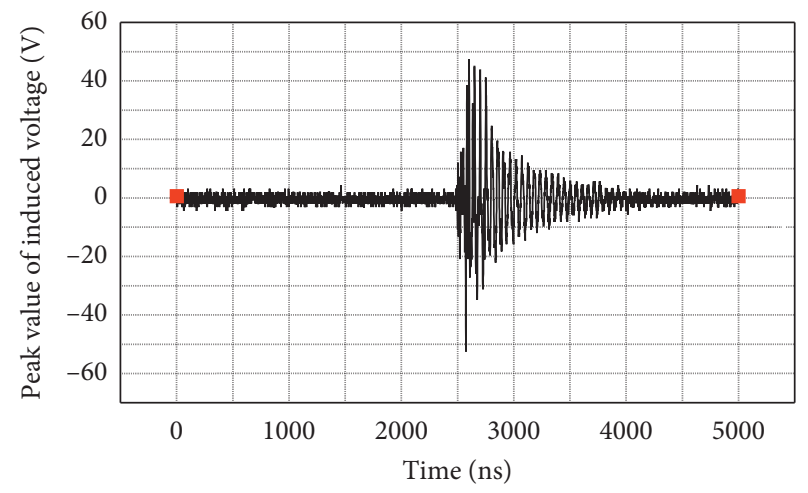

(h)

FiguRE 18: The induced voltage of discharge needle of different sizes in vertical direction. (a) $100 \mathrm{~mm}$. (b) $150 \mathrm{~mm}$. (c) $300 \mathrm{~mm}$. (d) $450 \mathrm{~mm}$. (e) $600 \mathrm{~mm}$. (f) $750 \mathrm{~mm}$. (g) $900 \mathrm{~mm}$. (h) Without metal electrode.

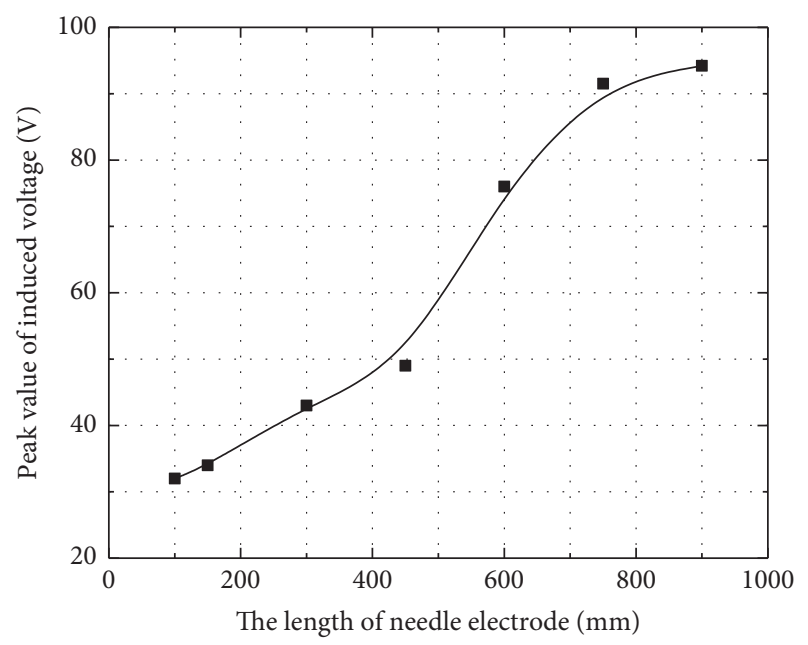

Figure 19: The relationship curve between discharge needle length and induced voltage.

breakdown under the condition of DC voltage. Then, we figured out the threshold value of spark breakdown under the effect of external radiation field. And at last, we analyzed the relationship between the threshold value of spark breakdown induced under external radiation field and external field strength, electrode length by comparing the two.
During the test, we set the needle electrode in the same direction as the applied electric field. Without external electric field radiation, the threshold voltage of continuous spark breakdown was $4.9 \mathrm{kV}$. When the electrode could be induced to $100 \%$ electric breakdown under the effect of the external field irradiation, the voltage between the electrodes was taken as the threshold value of the induced discharge. When the electrode length was less than $300 \mathrm{~mm}$, the uncertainty of the induced discharge threshold was larger than others. As shown in Table 1, we mainly list the test data with an electrode length of $300-900 \mathrm{~mm}$. The relationship between induced discharge threshold and electrode length is shown in Figure 22.

It can be seen from Table 1 and Figure 22 that the threshold value of induced discharge between the same discharge electrodes would decrease gradually with the increase of the peak electric field under the irradiation of UWB electromagnetic pulse with different peak electric fields. And the threshold value would decrease gradually with the increase of the electrode length under the action of UWB with the same peak electric field. According to the test results of coupling voltage of the metal electrode, the longer the length of metal electrode is, the greater the coupling voltage is, the greater contribution it will make to the induced discharge process, and finally, it will reduce the threshold value of induced discharge, which verifies the correctness of the simulation results in this article. 


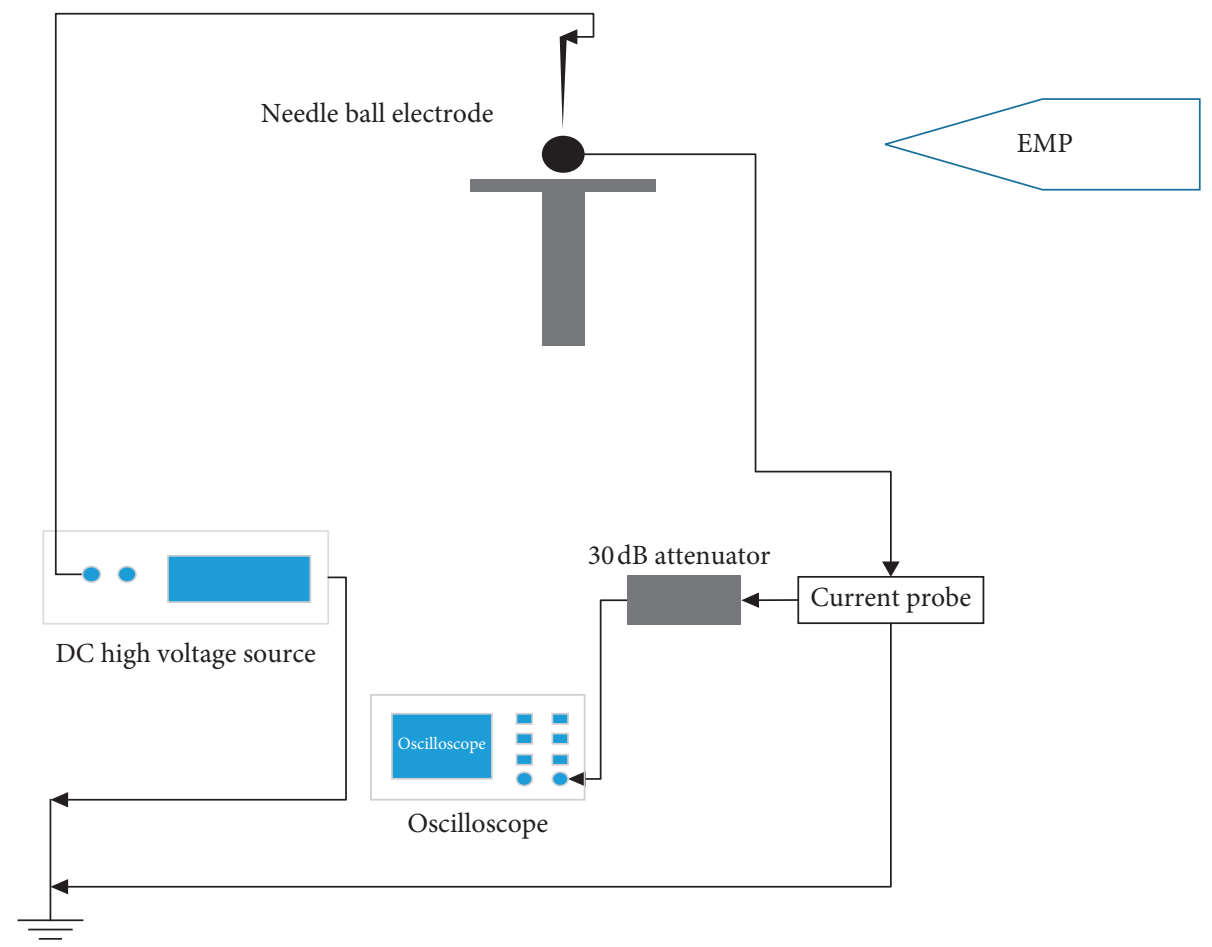

FIgURE 20: The principle diagram of induced discharge threshold characteristic test.

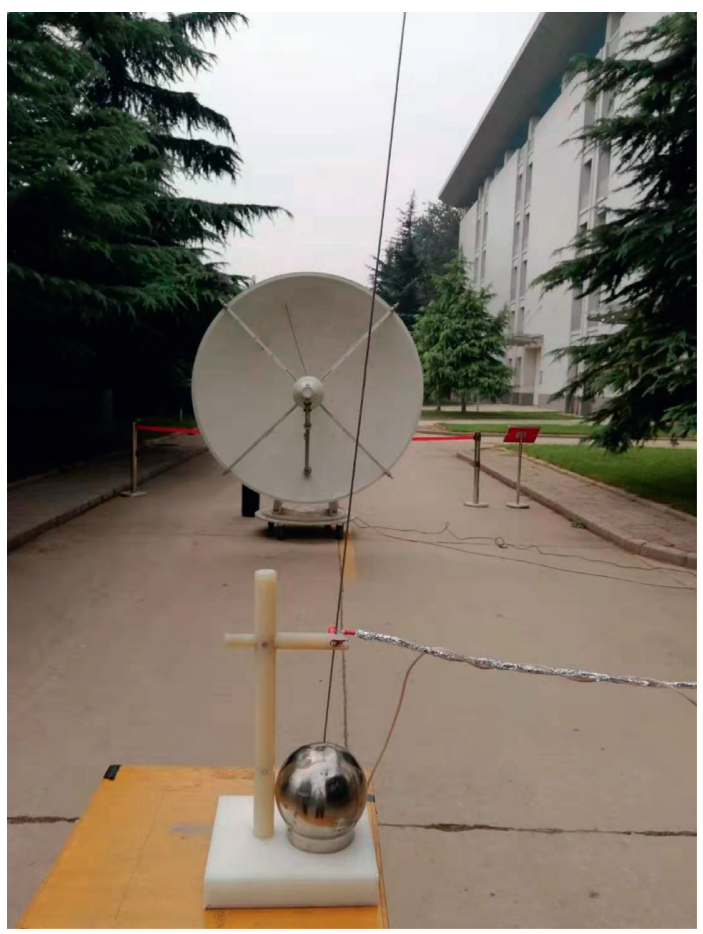

FIGURE 21: The test connection diagram.

TABLe 1: The induced threshold of different discharge needle lengths when electrode spacing was $3 \mathrm{~mm}$.

\begin{tabular}{|c|c|c|c|c|}
\hline The length of needle electrode $(\mathrm{mm})$ & $87(\mathrm{kV} / \mathrm{m})$ & $72(\mathrm{kV} / \mathrm{m})$ & $65(\mathrm{kV} / \mathrm{m})$ & $53(\mathrm{kV} / \mathrm{m})$ \\
\hline 900 & 4.0 & 4.1 & 4.4 & 4.5 \\
\hline 750 & 4.2 & 4.25 & 4.5 & 4.55 \\
\hline 600 & 4.3 & 4.4 & 4.58 & 4.6 \\
\hline 450 & 4.4 & 4.6 & 4.66 & 4.7 \\
\hline 300 & 4.5 & 4.7 & 4.72 & 4.8 \\
\hline
\end{tabular}

The threshold without external field discharge is $4.9 \mathrm{kV}$. 


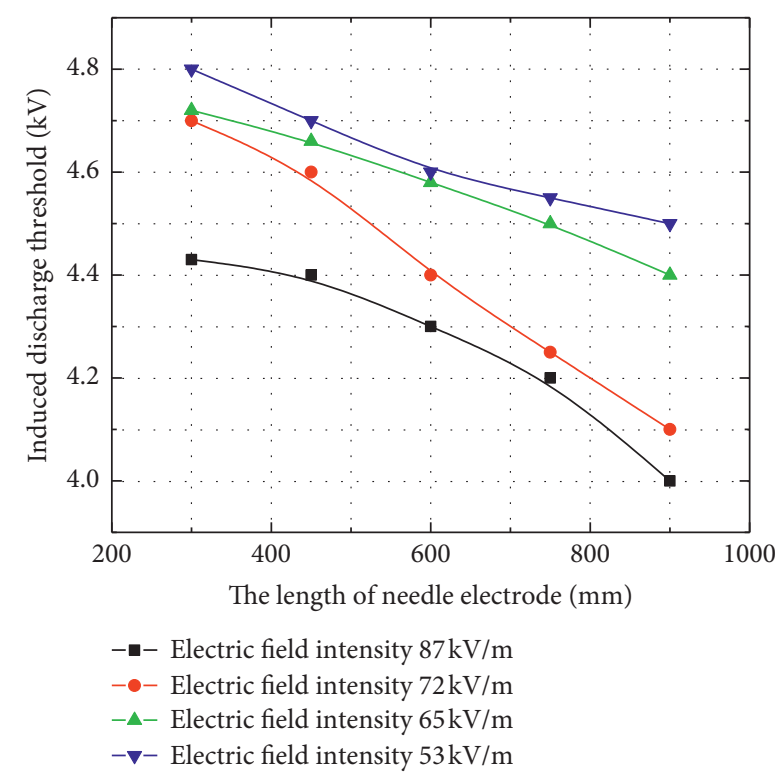

FIGURE 22: The relationship between induced discharge threshold and needle length.

\section{Conclusions}

The simulations' result shows that when the direction of the applied electric field was perpendicular to the metal needle electrode, the coupling voltage and the electric field in the gap of the metal needle electrode were very small, and the influence on the electrostatic discharge induction process could be ignored. When the direction of the applied electric field was parallel to the needle electrode, the peak value of the electric field formed at the gap was one order of magnitude larger than the amplitude of the applied electric field, and the peak field strength of the induced voltage and the peak field strength of the gap channel was directly proportional to the peak value of the applied electric field.

When the electrode size was small, the peak field strength of the induced electric field was one order of magnitude lower than that of the external radiation field, so that the external radiation field played a major role in the electrostatic discharge induction process. However, when the electrode size was large, the peak field strength of the induced electric field was one order of magnitude higher than that of the external radiation field; Therefore, the induced field of the metal electrode played a major role in the electrostatic discharge induction process.

When the diameter of the needle ball electrode's ball was fixed, the peak of induction voltage increased with the increase of the length of the needle electrode in a certain range. However, when beyond the certain range, the peak of induced voltage did not change anymore, and the maximum peak of induction voltage increased with the increase of the diameter of the ball. When the needle electrode's length was fixed, the peak of induction voltage increased with the increase of the diameter of the spherical electrode in a certain range; but when it exceeded over the certain range, the peak induction voltage did not change anymore either, and the maximum induced voltage varied with the length of the needle electrode. With the increase of the electrode size, the frequency corresponding to the peak of induction field would gradually decrease. And this is in accordance with the law that half-wave antenna has the strongest ability to receive electromagnetic waves.

It could be also seen from the verification test that the coupling voltage of the metal electrode had a great relationship with the polarization direction of the external electromagnetic field. When the direction of the metal electrode was parallel to the polarization direction of the external electromagnetic field, it would affect the electromagnetic field-induced discharge process. When the direction of the metal electrode was perpendicular to the polarization direction of the external electromagnetic field, the influence of metal coupling voltage on the process of electromagnetic field-induced discharge could be ignored, which was consistent with the simulation results.

For the same discharge electrode, the threshold value of induced discharge decreased with the increase of the peak value of the electric field under the irradiation of different peak electric fields of ultra-wideband electromagnetic pulse and decreased with the increase of electrode length under the action of ultra-wideband of the same peak electric field. According to the test results of coupling voltage of metal electrode, the longer the length of the metal electrode was, the greater the coupling voltage was; the greater the contribution of the metal electrode to the induced discharge process was, and the threshold value of induced discharge was reduced, which verifies the correctness of the simulation results.

\section{Data Availability}

The data used to support this study are obtained from the company's internal business secrets. Data sharing can only be carried out after the patent period of the company has expired.

\section{Conflicts of Interest}

The authors declare that they have no conflicts of interest.

\section{Acknowledgments}

This work was supported by the National Science Foundation of China (NSFC) with the number of 51777213.

\section{References}

[1] H. J. Wu, Y. D. Jiang, Z. Y. Zhang et al., "Active control of spacecraft surface potential," Journal of Shi Jia Zhuang Railway Institute (Natural Science), vol. 22, no. 4, pp. 40-42, 2006.

[2] W. Q. Feng, "Ground simulation test of large space geomagnetic sub-storm environment," Spacecraft Environmental Engineering, vol. 18, no. 4, pp. 33-42, 2001.

[3] X. Zhao and Z. Cai, "The impact of space environment and effectiveness on on-orbit spacecraft," in Proceedings of the Sixth Plenary Session of the Special Committee on Space Physics and Symposium on Space Environment Research and Forecast, Space Physics Professional Committee, Beijing, China, 2004. 
[4] C. Zhu, S. Liu, and W. Ming, "ESD radiation field measurement and research," Journal of Electronics, vol. 33, no. 9, pp. 1702-1705, 2005.

[5] B. Xu, Z. Wu, Y. Hao et al., "Spacecraft on-orbit space environment research," Journal of Hebei University of Science and Technology, vol. 32, no. Supplement 2, pp. 9-14, 2011.

[6] K. H. Wright, T. A. Schneider, J. A. Vaughn et al., "Electrostatic discharge testing of multijunction solar array coupons after combined space environmental exposures," IEEE Transactions on Plasma Science, vol. 40, no. 2, pp. 334-344, 2012.

[7] B. Xu, Q. Yuan, Z. Wu et al., "Ground simulation of electrostatic protection of aerospace materials under low pressure environment," High Voltage Engineering, vol. 39, no. 12, pp. 2894-2898, 2013.

[8] Q. Yuan, Y. Sun, X. Zhang et al., Spacecraft Electrification Theory and protection, National Defense Industry Press, Beijing, China, 2016.

[9] Y. A. Abdel-aziz and A. M. A. el-hameed, "Ground-based simulation for the effects of space plasma on spacecraft," Advances in Pace Research, vol. 28, no. 51, pp. 133-142, 2013.

[10] S. T. Lai, Fundamentals of Spacecraft Charging-Spacecraft Interactions with Space plasma, Princeton University Press, Princeton, NJ, USA, 2012.

[11] C. Zhao, D. Li, S. Yang et al., "Surface charging and its environment influencing factors for low earth orbit spacecraft," High Voltage Engineering, vol. 43, no. 5, pp. 1438-1444, 2017.

[12] S. Liu, W. Guanghui, and Z. Liu, Electrostatic Theory and Protection, Weapon Industry Press, Beijing, China, 1999.

[13] Y. Liu, H. Zhao, Yi Zhong et al., "Analysis and Countermeasures of space station electrification effect," Manned Space Flight, vol. 19, no. 5, pp. 6-12, 2013.

[14] T. Zhang, "New progress of electric propulsion in lanzhou institute of space technology physics," Rocket Propulsion, vol. 41, no. 2, pp. 7-12, 2015.

[15] L. Shengtao, Z. Xiaoquan, C. Yu et al., Shutl Principle of Spacecraft Electrification, Science Press, Beijing, China, 2015.

[16] R. Quan, J. Han, J. Huang et al., "Model study on radiation induced conductivity of dielectric materials," Acta Physica Sinica, vol. 56, no. 11, pp. 6642-6647, 2007.

[17] M. Xue, "Research on ESD effect and protection technology of high pressure gaas solar array," Dissertation, Tianjin University, Tianjin, China, 2007.

[18] B. Huang and J. Tong, Space Environmental Engineering, China Science and Technology Press, Beijing, China, 2010.

[19] X. Hu, S. Liu, L. Wang et al., "Calculation and experiment of corona discharge radiation field of advanced conductor," High Voltage Technology, vol. 38, no. 9, pp. 2266-2272, 2012.

[20] H. Cao, Z. Ma, H. Liu et al., "Simulation test system of vacuum corona discharge induced by electromagnetic field irradiation," Intense Laser and Particle Beam, vol. 28, no. 8, pp. 112-115, 2016.

[21] H. Yongqiang, W. Jiao, and H. Chen, "Using Monte Carlo method to calculate the internal charging effect of the electronic storm event on the satellite subsystem in July 2004," Progress in Geophysics, vol. 24, no. 6, pp. 1937-1942, 2009.

[22] Y. Zhang, S. Liu, X. Hu et al., "Detection system and identification method of corona discharge radiation signal," High Voltage Technology, vol. 40, no. 9, pp. 2813-2819, 2014.

[23] L. Zhu, M. Qiao, Y. Liu et al., "Electrostatic discharge test and analysis of LEO spacecraft high voltage and high power solar array," Spacecraft Engineering, vol. 24, no. 4, pp. 65-70, 2015.
[24] J. Han, J. Huang, Z. Liu, and S. Wang, "Correlation of double star anomalies with space environment," Journal of Spacecraft and Rockets, vol. 42, no. 6, pp. 1061-1065, 2005.

[25] H. Liu, S. Liu, W. Ming et al., "Research of corona discharge characteristics for low pressure at high altitude based on simulation experiments," High Voltage Engineering, vol. 41, no. 5, pp. 1704-1708, 2015.

[26] B. Zhang, T. Wang, Y. Li, H. Fan, L. Gao, and C. Duan, "Numerical simulation and experimental study for lowpressure direct-current low discharge," High Voltage Engineering, vol. 42, no. 3, pp. 724-730, 2016.

[27] Z. Duan, S. Qiu, S. Zang, X. Si, Z. Li, and H. Zu, "Parameters influencing the electrostatic discharge performance of aircraft static discharges," High Voltage Engineering, vol. 42, no. 5, pp. 1356-1362, 2016.

[28] J. Yang, Gas Discharge, Science Press, Beijing, China, 1983.

[29] Z. Wu, X. Zhang, and Y. Hu, Gas Discharge, National Defense Industry Press, Beijing, China, 2012.

[30] X. Hu, Gas Discharge and Plasma, Harbin Institute of Technology Press, Harbin, China, 1994.

[31] Y. Fu, Study on Similarity of Gas Discharge at Low pressure, Tsighua University Press, Beijing China, 1983. 